\title{
INCUBATION TIME OF ISOTHERMALLY TRANSFORMED ALLOTRIOMORPHIC FERRITE IN MEDIUM CARBON STEELS
}

\author{
C. CAPDEVILA ${ }^{1,2}$, C. GARCÍA DE ANDRÉS ${ }^{1}$ and F. G. CABALLERO ${ }^{1}$ \\ ${ }^{1}$ Department of Physical Metallurgy, Centro Nacional de Investigaciones Metalúrgicas (CENIM), Consejo \\ Superior de Investigaciones Científicas (CSIC), Avda. Gregorio del Amo, 8, 28040 Madrid, Spain \\ ${ }^{2}$ Department of Materials Science and Metallurgy, University of Cambridge, Pembroke Street, Cambridge \\ CB2 3QZ, UK
}

Keywords: steels, phase transformations, modelling, nucleation

\section{Introduction}

Medium carbon microalloyed steels have become of great interest because of the possibility to form mainly acicular ferrite microstructures after the forging process of these steels. An important improvement in toughness has been reached in these steels as comparison with those with a conventional ferrite-pearlite microstructure [1-5]. These steels are developed for the automotive, offshore oil and gas industries, and are designed to be in service in corrosive environment.

In medium carbon microalloyed steels, acicular ferrite is always formed after the growth of allotriomorphic ferrite and pearlite [4]. As a consequence, acicular ferrite transformation is expected to be influenced by the previous allotriomorphic ferrite formation. The role of the allotriomorphic ferrite to promote the formation of acicular ferrite to the detriment of bainite has been reported in previous works [1,6-8]. Thus, the amount of acicular ferrite increases, as allotriomorphic ferrite is present along the austenite grain boundaries of medium carbon microalloyed steels. Therefore, a deep understanding of the decomposition of austenite in allotriomorphic ferrite is needed in order to control the total amount of acicular ferrite. In this sense, a theoretical prediction of the incubation time for allotriomorphic ferrite transformation can be useful for the development of medium carbon microalloyed steels.

A great number of attempts, from purely empirical to semiempirical models, have been made to predict the start of ferrite transformation [9-10]. However, models recently developed are becoming less empirical since they rely on thermodynamic and phase transformation theories [11]. In principle, most of these models are able to predict the incubation time of ferrite allotriomorphs for low carbon low alloy steels. But, the level of agreement between predicted and calculated incubation times for allotriomorphic ferrite is less satisfactory for medium carbon steels. The purpose of this study is to predict the incubation time for allotriomorphic ferrite formation in medium carbon microalloyed steels. The influence of alloying elements on carbon diffusion of in austenite has been considered.

\section{Experimental Procedure}

The chemical composition of three different medium carbon steels is listed in Table 1. A conventional carbon manganese steel (CMn), and two different microalloyed steels (VTi1 and VTi2) with very different Ti content have been considered in this study. The isothermal decomposition of austenite has been analysed by means of an Adamel Lhomargy DT1000 high-resolution dilatometer described elsewhere [12]. The heating device consists of a very low thermal inertia radiation furnace. The heat radiated by two tungsten filament lamps is focussed on the specimen (cylindrical test pieces of 2-mm in diameter and 12-mm in length) by means of a bielliptical reflector. The temperature is measured with a $0.1 \mathrm{~mm}$ in diameter, Chromel-Alumel (Type K) thermocouple spot welded to the specimen. Blowing a jet of helium gas directly onto the specimen surface 
induces cooling. The helium flow rate during cooling is controlled by a proportional servovalve. These devices ensure an excellent efficiency in controlling the temperature and holding time of isothermal treatments and fast cooling in quenching processes.

TABLE 1

Composition of steels (wt. \%)

\begin{tabular}{ccccccccccc}
\hline Steels & $\mathrm{C}$ & $\mathrm{Mn}$ & $\mathrm{N}$ & $\mathrm{Si}$ & $\mathrm{Cu}$ & $\mathrm{Cr}$ & $\mathrm{Ni}$ & $\mathrm{Ti}$ & $\mathrm{V}$ & $\mathrm{Mo}$ \\
\hline CMn & 0.31 & 1.22 & - & 0.253 & - & 0.138 & 0.098 & - & 0.004 & 0.03 \\
VTi1 & 0.37 & 1.45 & 0.0162 & 0.56 & 0.14 & 0.04 & - & 0.015 & 0.11 & 0.025 \\
VTi2 & 0.32 & 1.39 & 0.0148 & 0.33 & 0.129 & 0.13 & 0.14 & 0.039 & 0.129 & 0.03 \\
\hline
\end{tabular}

As it is well known, prior austenite grain size (PAGS) exerts an important influence on the decomposition of austenite [13]. Austenitisation conditions were selected to achieve approximately the same PAGS in all the steels (Table 2). After austenitisation, specimens were isothermally transformed at temperatures in the range of 973 to $873 \mathrm{~K}$ at different times and subsequently were gas-quenched under helium gas flow at a cooling rate of $200 \mathrm{~K} / \mathrm{s}$.

TABLE 2

Austenitisation Conditions

\begin{tabular}{cccc}
\hline Steels & Temperature, $(\mathrm{K})$ & Time, $(\mathrm{s})$ & PAGS, $(\mu \mathrm{m})$ \\
\hline CMn & 1473 & 120 & 70 \\
VTi1 & 1523 & 60 & 76 \\
VTi2 & 1523 & 180 & 72 \\
\hline
\end{tabular}

Specimens were ground and polished using standardised metallographic techniques. Nital-2pct etching solution was used to reveal the ferrite microstructure by optical microscopy. The PAGS was calculated on recorded micrographs by using a linear intercept technique, involving at least 50 intercepts, permitting the count of the number of grains intercepted by the grid line. The effects of a moderately non-equiaxial structure may be eliminated by counting the intersections of lines in four or more orientations covering all the observation fields with an approximately equal weight [14].

\section{$\underline{\text { Results and Discussion }}$}

According to the classical nucleation theory, the nucleation rate for the allotriomorphs, $I$, is expressed as follows [15]:

$$
I=I_{0} \exp \left(-\frac{\tau}{t}\right)
$$

where $I_{0}$ is the steady state nucleation rate, $t$ is the isothermal reaction time, and $\tau$ is the incubation time. Lange et al. [16] proposed a model to calculate $I$ based on a traditional disk-shaped 'pillbox' nucleus. In that case, $I$ is estimated as follows,

$$
I \propto \exp \left\{-\frac{12 k_{B} T a^{4} \sigma_{\alpha \gamma}}{D_{C}^{\gamma} \bar{x} v_{\alpha}^{2} \Delta G_{v}^{2} t}\right\}
$$

where $k_{B}$ is Boltzmman constant; $D_{C}^{\gamma}$ is the diffusivity of carbon in austenite; $v_{\alpha}$ is the volume of an atom of iron in ferrite; $a$ is the average of the lattice parameters of both phases, ferrite and austenite for a given 
temperature and steel composition; $\bar{x}$ is the average carbon content of the steel in mole fraction; $\Delta G_{v}$ is the volume free energy change associated to the formation of the nucleus; $\sigma_{\alpha \gamma}$ is the interfacial energy of a disorder ferrite; and $T$ is the isothermal temperature. From a comparison between equations (1) and (2), an expression for the incubation time can be obtained straightforward:

$$
\tau=\frac{12 k_{B} T a^{4} \sigma_{\alpha \gamma}}{D_{C}^{\gamma} \bar{x} v_{\alpha}^{2} \Delta G_{v}^{2}}
$$

The theoretical determination of $D_{C}^{\gamma}$, performed by Siller and McLellan [17] and reviewed by Bhadeshia [18], considers both the kinetic and equilibrium thermodynamic behaviour of carbon in austenite. Calculation of $D_{C}^{\gamma}$ takes also into account two important factors: the concentration dependence of the activity of carbon in austenite [19] and the repulsive interactions between nearest neighbouring carbon atoms located in octahedral interstitial sites [20]. Thus, the diffusivity $D_{C}^{\gamma}$ is calculated by two factors, a concentration dependent factor and a concentration independent factor,

$$
D_{C}^{\gamma}=\xi(\theta) \frac{k_{B} T}{h}\left(\frac{\lambda^{2}}{3 \gamma_{m}}\right) \exp \left\{-\frac{\Delta G^{*}}{k_{B} T}\right\}
$$

where $\xi(\theta)$ is the carbon concentration dependent factor obtained according to Bhadeshia's calculations [18] and takes values listed in Table $3 ; \Delta G^{*}$ is the activation free energy for diffusion which is independent of composition and temperature; $\gamma_{m}$ is an activity coefficient assumed constant; $\lambda$ is the distance between the $\{002\}$ austenite planes and $h$ is the Planck's constant. Bhadeshia [18] found that $\Delta G^{*} / k_{B}=21230 \mathrm{~K}$ and $\ln \left\{\gamma_{m} / \lambda^{2}\right)=31.84$. Likewise, Babu and Bhadeshia [21] completed this model analysing the effect of different substitutional alloy elements on the diffusivity of carbon in austenite. The values of $D_{C}^{\gamma}$ for temperatures ranging from $973 \mathrm{~K}$ to $873 \mathrm{~K}$ are listed in Table 4.

TABLE 3

Calculated Values of $\xi(\theta)$ Factor at Different Temperatures for the Three Steels

\begin{tabular}{cccc}
\hline$T,(\mathrm{~K})$ & CMn & VTi1 & VTi2 \\
\hline 973 & 0.007 & 0.009 & 0.011 \\
948 & 0.012 & 0.013 & 0.012 \\
923 & 0.014 & 0.015 & 0.014 \\
898 & 0.016 & 0.017 & 0.016 \\
873 & 0.019 & 0.023 & 0.011 \\
\hline
\end{tabular}

The volume free energy change, $\Delta G_{v}$, in equation (3) has been calculated with the help of a commercial software namely MTDATA [22], which contains a large and rigorously evaluated thermodynamic database. $\Delta G_{v}$ calculations take into account the effect of all the alloying elements in the decomposition of austenite. The values obtained for the studied steels are listed in Table 4.

In order to determine $a$ in equation (3), it is needed to calculate previously the lattice parameters of ferrite and austenite. The ferrite lattice parameter has been estimated using the relationships given by Leslie [23] and Bhadeshia [24], which take into consideration the equilibrium dissolved carbon in ferrite as well as the different substitutional alloying elements. On the other hand, the austenite lattice parameter has been calculated as reported by Ridley et al. [25] and Dyson and Holmes [26] considering the dependence of the lattice parameter of austenite on alloying elements. The values of $a$ at temperatures ranging from $973 \mathrm{~K}$ to $873 \mathrm{~K}$ are also listed in Table 4. 
TABLE 4

Calculated Values of $\Delta G_{v} D_{C}^{\gamma}$ and $a$ Parameters at Different Temperatures for the Three Steels

\begin{tabular}{cccccccccc}
\hline \multicolumn{9}{c}{$\mathrm{CMn}$} & \multicolumn{1}{c}{ VTi1 } \\
\hline$T$ & $\begin{array}{c}D_{C}^{\gamma} \times 10^{-14} \\
\left(\mathrm{~m}^{2} \mathrm{~s}^{-1}\right)\end{array}$ & $\begin{array}{c}\Delta G_{v} \times 10^{7} \\
\left(\mathrm{~J} \mathrm{~m}^{-3}\right)\end{array}$ & $\begin{array}{c}a \\
(\mathrm{pm})\end{array}$ & $\begin{array}{c}D_{C}^{\gamma} \times 10^{-14} \\
\left(\mathrm{~m}^{2} \mathrm{~s}^{-1}\right)\end{array}$ & $\begin{array}{c}\Delta G_{v} \times 10^{7} \\
\left(\mathrm{~J} \mathrm{~m}^{-3}\right)\end{array}$ & $\begin{array}{c}a \\
(\mathrm{pm})\end{array}$ & $\begin{array}{c}D_{C}^{\gamma} \times 10^{-14} \\
\left(\mathrm{~m}^{2} \mathrm{~s}^{-1}\right)\end{array}$ & $\begin{array}{c}\Delta G_{v} \times 10^{7} \\
\left(\mathrm{~J} \mathrm{~m}^{-3}\right)\end{array}$ & $\begin{array}{c}a \\
(\mathrm{pm})\end{array}$ \\
\hline 973 & 24.0 & -1.62 & 330.5 & 30.9 & -0.96 & 330.6 & 36.4 & -1.11 & 331.7 \\
948 & 22.5 & -2.69 & 330.4 & 24.3 & -2.00 & 330.5 & 22.7 & -2.07 & 331.5 \\
923 & 13.7 & -3.83 & 330.2 & 14.8 & -3.23 & 330.3 & 13.8 & -3.21 & 331.4 \\
898 & 8.1 & -5.30 & 330.0 & 8.7 & -4.48 & 330.2 & 8.2 & -4.53 & 331.2 \\
873 & 4.6 & -6.03 & 329.9 & 5.8 & -5.94 & 330.0 & 2.7 & -6.28 & 331.1 \\
\hline
\end{tabular}

Likewise, a $\sigma_{\alpha \gamma}$ value of $0.705 \mathrm{~J} \mathrm{~m}^{-2}[16,27]$ and an atomic radius of iron atom into ferrite lattice of $128 \mathrm{pm}$ [28] $\left(v_{\alpha}=8.785 \times 10^{-30} \mathrm{~m}^{3}\right)$ have been considered in equation (3) for $\tau$ calculations.

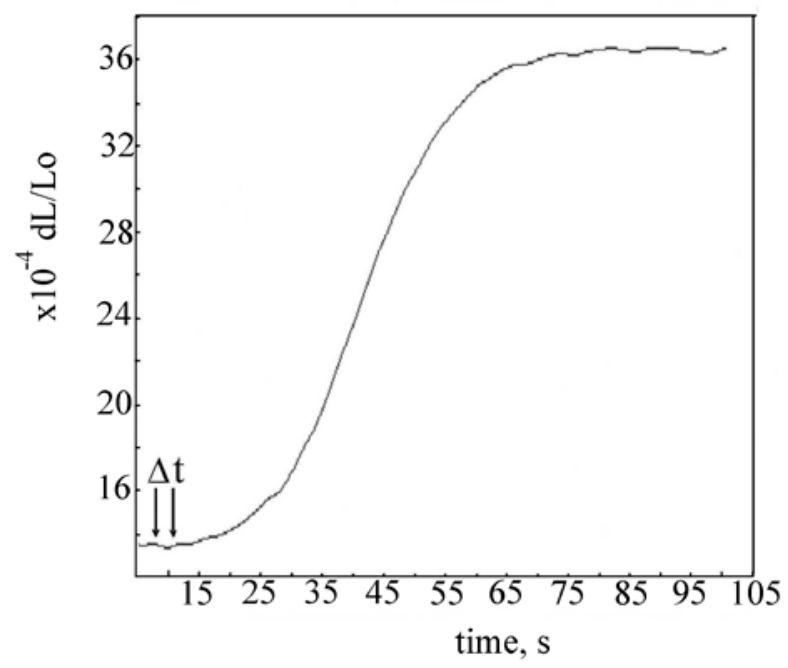

Figure 1. Dilatometric curve (relative change in length vs time) obtained during isothermal decomposition of austenite at $873 \mathrm{~K}$ during $100 \mathrm{~s}$ for VTi1 steel.

Figure 2. Optical micrograph of VTi2 steel after isothermal heat treatment at $898 \mathrm{~K}$ during $8 \mathrm{~s}$.

The experimental validation of incubation time calculations has been carried out by dilatometry and metallography. The experimental incubation time is defined as the minimum time at which it is possible to detect some allotriomorphs nucleated on the austenite grain boundary. A detailed analysis of the dilatometric curve associated to the isothermal decomposition of austenite (relative change of length $(d L / L o$ ) versus time $(t)$ ) (Fig. 1) allows to determine an interval of time, $\Delta t$, in which it is more likely to find the incubation time. Subsequent samples were isothermal heat treated at different holding times within the $\Delta t$ interval. An accurate metallographic analysis of those samples determined the incubation time at which some allotriomorphs appear in the microstructure. Figure 2 shows an example of a microstructure with allotriomorphs at the initial stage of 
their formation. Figure 3 shows a comparison between calculated (dashed line) and experimental (points) incubation time values for the studied steels. From this figure it can be concluded that calculated results for the incubation time are in good agreement with the predicted values from calculations proposed in this work for all the studied steels. Figure 4 presents the experimental and calculated incubation time values at the different isothermal temperatures of transformation for the three steels. Points lying on the line of unit slope show a perfect agreement between experimental and calculated values. $\mathrm{R}^{2}$ in Fig. 4 is the square correlation factor of the experimental and calculated incubation time values. This parameter quantifies the accuracy of the calculations. An accuracy better than $90 \%$ which can be considered excellent bearing in mind the experimental difficulties for the experimental determination of the incubation time.

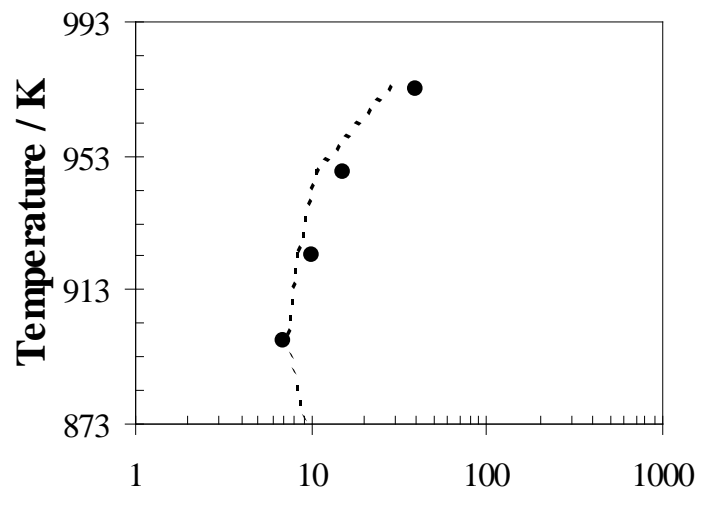

Time / s

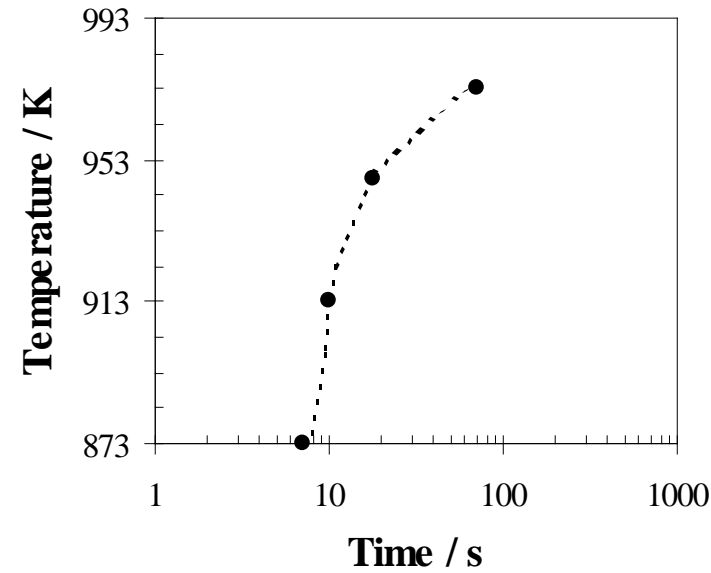

(b)

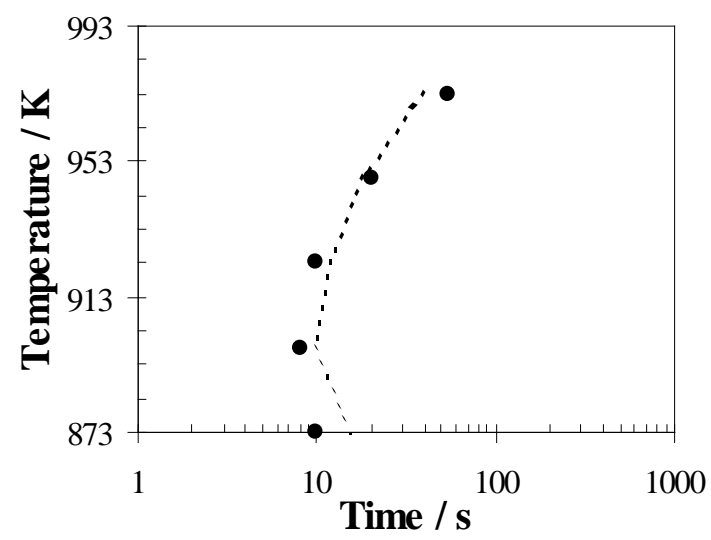

(c)

Figure 3. Experimental and calculated results for the incubation time of isothermally formed allotriomorphic ferrite in (a) CMn, (b) VTi1, and (c) VTi2 steels.
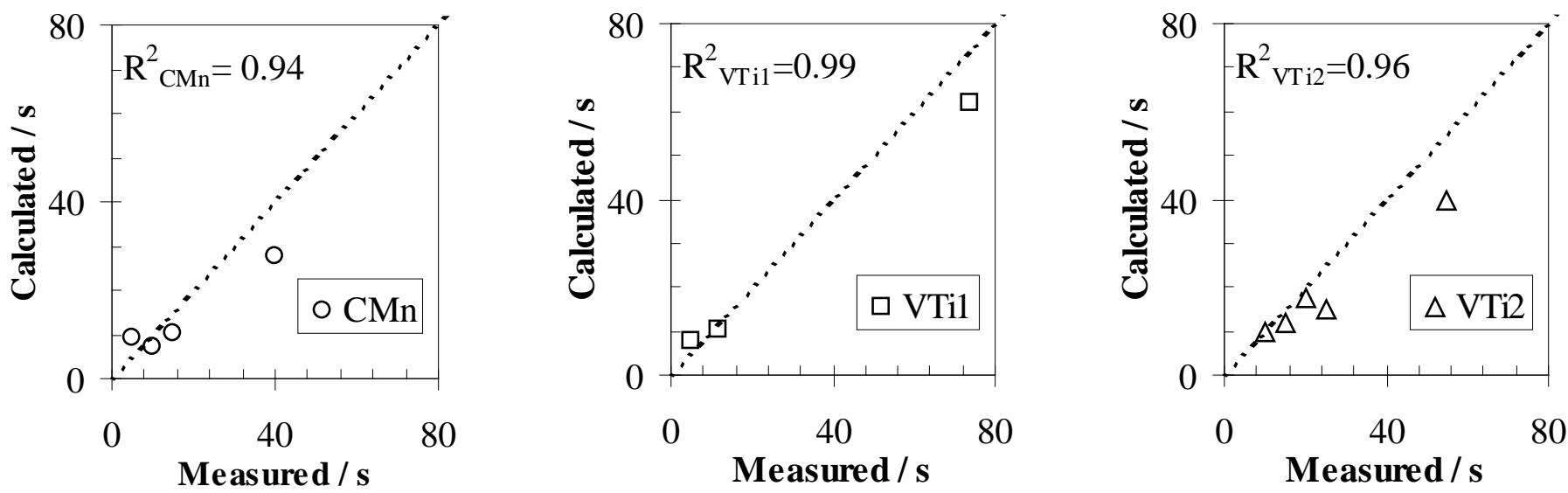

Figure 4. A comparison between calculated and experimental incubation time values in the three studied steels. 


\section{Conclusions}

A mathematical process to calculate the incubation time of allotriomorphic ferrite isothermally formed in three medium carbon steels have been described. Calculations are based on well known phase transformation theories in steels. The influence of the alloying elements on the nucleation of allotriomorphic ferrite has been taken under consideration in calculations via an evaluation of their effect in the diffusivity of carbon and in the volume free energy change estimations.

Finally, experimental validation of calculations has been carried out using dilatometric and metallographic analysis. An excellent agreement $\left(96 \%\right.$ in $\mathrm{R}^{2}$ ) between calculated and measured incubation time values for the isothermal formation of allotriomorphic ferrite has been found in the three medium carbon steels.

\section{Acknowledgements}

The authors acknowledge financial support from the Spanish Comisión Interministerial de Ciencia y Tecnología (CICYT) (project-PETRI 95-0089-OP). GSB Acero S.A and CEIT are thanked for providing the steel and their collaboration in this project.

\section{References}

[1] García De Andrés C, Capdevila C and Caballero FG, Proceedings of The Congreso Nacional de Tratamientos Térmicos y de Superficie TRATERMAT 98, Madrid: Eds: M. Carsi et al. (Cenim-Csic), 1998:135.

[2] Madariaga I and Gutiérrez I, Acta Mater. 1999;47:951.

[3] García De Andrés C, Capdevila C and Caballero FG, Proceedings of The International Conference on Materials in Oceanic Environment EUROMAT 98, Lisbon: Ed: L. Faria, (Spm, Fems), 1998:217.

[4] Madariaga I, Gutiérrez I, García De Andrés C and Capdevila C, Scripta Mater. 1999;41:229.

[5] Madariaga I, Romero JL and Gutierrez I, Metall. Trans. A. 1998;29A:1003.

[6] Bhadeshia HKDH, Mater. Sci. Technol. 1985;1:497.

[7] Babu SS, Bhadhesia HKDH and Svensson LE, J. Mater. Sci. Lett. 1991;10:142.

[8] Babu SS and Bhadhesia HKDH, Mater. Sci. Technol. 1990;6:1005.

[9] Kirkaldy JS, Metall. Trans. 1973;4:237.

[10] Sharma RC and Purdy G, Metall. Trans. 1974;5:939.

[11] Bhadeshia HKDH, Metal Sci. 1982;16:159.

[12] García de Andrés C, Caruana G and Alvarez LF, Mater. Sci. Eng. 1998;A241:211.

[13] Sinha AK, Ferrous Physical Metallurgy, Boston: Butterworths,1989:379.

[14] Vander Voort GF, Metallography. Principles and Practice, New York: Mcgraw-Hill Book Company, 1984:247.

[15] Russell KC, Phase Transformations, Metals Park, OH: Ed. H. I. Aaronson, ASM, 1970:217.

[16] Lange WF, Enomoto M and Aaronson HI, Metall. Trans. 1988;19A:427.

[17] Siller RH and Mclellan RB, Metall. Trans. 1970;1:985.

[18] Bhadeshia HKDH, Metal Sci. 1981;15:477.

[19] Smith RP, J. Am. Chem. Soc. 1946;68:1163.

[20] Mclellan RB and Dunn W, J. Phys. Chem. Solids. 1969;30:2631.

[21] Babu SS and Bhadeshia HKDH, J. Mat. Sci. Lett. 1995;14:314.

[22] Hodson SM, MTDATA-Metallurgical and Thermomechanical Databank, Teddington: National Physical Laboratory, 1989:1.

[23] Leslie WC, Physical Metallurgy of Steels, International Student Edition, New York: Mcgraw-Hill, 1982:111.

[24] Bhadeshia HKDH, Map Project, http://www.msm.cam.ac.uk/map/steel/subs/ferr-b.html.

[25] Ridley N, Stuart H and Zwell L, Trans. AIME. 1969;245:1834.

[26] Dyson DJ and Holmes B, JISI. 1970;208:469.

[27] Gjostein NA, Domian HA, Aaronson HI and Eichen E, Acta Metall. 1966; 4:1637.

[28] Honeycombe RWK and Bhadeshia HKDH, Steels: Microstructure and Properties, London: Ed. Arnold, 1995:5. 